\title{
Impact of value perceptions on luxury purchase intentions: a developed market comparison
}

\section{Michael Chattalas*}

College of Business and Public Management,

Kean University,

Union, NJ 07083, USA

Email: mchattal@kean.edu

*Corresponding author

\section{Paurav Shukla}

Glasgow School for Business and Society,

Glasgow Caledonian University,

London - E1 6PX, UK

Email: Paurav.Shukla@gcu.ac.uk

\begin{abstract}
Consumers derive subjective worth of any product of service based on their value perceptions. This study measures the impact of value perceptions on luxury consumption purchase intentions focusing on two of the largest luxury markets holding significant referent influence on consumers worldwide - namely the UK and the USA. Cross-sectional, survey-based methodology and structural equation modelling was employed to collect and analyse the data. The findings suggest that while functional value perceptions drive luxury consumption purchase intentions across both nations, social value has a significant contribution only among US consumers and personal value perceptions only in the UK. The results provide managers opportunities for strategic differentiation and brand positioning of their luxury brand in a cross-national context. The findings demonstrate that while the USA and the UK remain fairly similar on most macro cultural traits, consumer value perceptions differ significantly. Hence, a cautionary approach is advised in making generalised assumptions using national-level cultural indicators at consumer-level decision making.
\end{abstract}

Keywords: luxury; value perceptions; social perceptions; personal orientation; functional perceptions; structural equation modelling; purchase intentions; cross-cultural; cross-national.

Reference to this paper should be made as follows: Chattalas, M. and Shukla, P. (2015) 'Impact of value perceptions on luxury purchase intentions: a developed market comparison', Luxury Research J., Vol. 1, No. 1, pp.40-57.

Biographical notes: Michael Chattalas is an Assistant Professor and Academic Coordinator of Marketing at the College of Business and Public Management, Kean University, USA. He holds a $\mathrm{PhD}$ in Marketing and International Business from The City University of New York (Baruch College). He has published scholarly papers (in International Marketing Review, Journal of Consumer Marketing, Services Marketing Quarterly and Place Branding and Public Diplomacy) and presented at global conferences and industry workshops 


\begin{abstract}
on international marketing and consumer behaviour topics such as, nation-branding and stereotypes, luxury consumption, sustainability and cross-cultural issues.

Paurav Shukla is a Professor of Luxury Brand Marketing at Glasgow Caledonian University, UK. His research interests include cross-cultural consumer behaviour, luxury marketing and branding, and digital marketing. His career began in industry, and he continues to work hand in hand with corporations. He has published many articles in top-tier academic journals, including Journal of Business Research, Journal of World Business, International Marketing Review, Psychology \& Marketing and Information \& Management among others. Popular accounts of his work have appeared in the mainstream press such as The Sunday Times, Business Week, National Post of Canada, LiveMint, and The Wall Street Journal, among others.
\end{abstract}

\title{
1 Introduction
}

Luxury goods are defined as conducive to pleasure and comfort and also, hard to obtain. Building on the definition by Vigneron and Johnson (2004), we posit that luxury products can - either alternatively or cumulatively - deliver personal indulgence and social esteem on consumers, aside from the functional utility of owning or experiencing a good or service that offers superior value in terms of quality, design, performance, durability and overall customer satisfaction. Hence, by providing exceptional value and overall excellence, luxury products enable consumers to satisfy both or either of their socio-psychological and functional needs (Shukla, 2012; Wiedmann et al., 2007; Hennigs et al., 2012).

Value derived from a product or services is one of the inherent drivers of consumer purchase decisions. In that regard, Zeithaml (1988) defines value as an overall assessment of subjective worth of a product or service considering all relevant evaluative criteria. Research on luxury value demonstrates the debate developing on three fundamental dimensions namely social, personal and functional value perceptions (Wiedmann et al., 2007; Shukla and Purani, 2012; Hennigs et al., 2012). In this paper, we focus on simultaneously testing the relative effect of these underlying dimensions of luxury value across two leading luxury markets, the USA and the UK. Briefly, social value is driven by the drive to project a desirable image to others (Kapferer, 1997; Shukla, 2012), personal value by the experiential and symbolic benefits to the self (Wong and Ahuvia, 1998), and functional value by utilitarian factors (Wiedmann et al., 2007).

Consumers hardly ever take decisions in isolation. They consider multiple factors when purchasing high-involvement products such as luxury brands. However, researchers assert that the influence of value perceptions has been looked in isolation and therefore our resultant understanding of luxury consumption is partial and uni-dimensional (Vigneron and Johnson, 2004; Shukla, 2012; Tynan et al., 2010; Wiedmann et al., 2009). Kapferer (1997) states that luxury consumption is a multi-dimensional phenomenon and hence, the earlier efforts which predominantly analyse only a single construct relating to value perceptions may not provide conclusive answers relating to the cultural stability of the luxury consumption construct (Shukla and Purani, 2012). Building on the earlier work carried out by Vigneron and Johnson (2004), Wiedmann et al. (2007) proposed a 
conceptual framework focusing on multiple dimensions of luxury value perceptions. Additionally, Tynan et al. (2010) note that since the debate in the area of value perceptions has largely been theoretical in nature, empirical support is required to increase the validity and reliability of the constructs. Furthermore, with the increasing global nature of the luxury business, researchers have called for cross-national and cross-cultural studies addressing the issue of luxury consumption (Dubois et al., 2005; Shukla and Purani, 2012; Wiedmann et al., 2009).

The purpose of this paper is to develop and test a model which measures the impact of value perceptions on luxury purchase intentions. The simultaneous examination via use of structural equation modelling will enable us to identify the magnitude of the effects of value perceptions (i.e. social, personal and functional) in the presence of other constructs. By proposing and empirically testing the influence of value perceptions across two nations (USA and UK) we also provide first insights into the cultural stability of the constructs proposed in two largely homogenous markets from a national cultural traits (such as collectivism-individualism, power distance, etc.) perspective (Hofstede and Hofstede, 2004; Trompenaars and Hampden-Turner, 1998). In this regards, the study contributes to the debate relating to the use of national level cultural traits for consumer level decision making. If the findings demonstrate homogeneity between national level cultural traits and consumer level decision making, this would offer an opportunity to standardise marketing campaigns. Findings in the contrary would provide an avenue for customisation of the campaigns. As a result, the current study contributes to a more holistic understanding of the luxury consumption phenomenon.

The next sections are organised as follows: First, we present a conceptual framework based on a literature review of prior research on luxury consumption. This framework is organised around the three fundamental dimensions that underlie value perceptions; i.e. social, personal, and functional. Next, we propose research hypotheses pertinent to luxury purchase intentions across nations. Then, we present the methodology and results of a cross-national study (in the UK and USA) testing the above hypotheses. The final section discusses the empirical findings, reconciles them with the conceptual framework and discusses the practical implications along with limitations and directions for future research.

\section{Literature review and hypotheses development}

Luxury consumption has been present in diverse forms since the beginning of human civilisation. Its role was just as important in ancient Western and Eastern empires as in modern societies (Wong and Ahuvia, 1998). In contemporary marketing usage, 'luxury' refers to a specific (i.e. higher-priced) tier of offer in almost any product or service category (Dubois et al., 2005).

In the past few decades luxury consumption has been studied in a variety of disciplines including, historical analysis (Mason, 1999; Wong and Ahuvia, 1998), econometric modelling (Ait-Sahalia et al., 2004), economic psychology (O'Cass and Frost, 2002; Hennigs et al., 2012); and marketing (e.g. Dubois and Laurent, 1994; Kapferer, 1997; Vigneron and Johnson, 2004; Shukla and Purani, 2012; Wiedmann et al., 2007). However, despite the substantial body of knowledge accumulated during the past decades, empirical research on the topic of consumer attitudes toward luxury is still rather scarce (Dubois et al., 2005; Shukla, 2012). 
Furthermore, while the word 'luxury' is used in daily lives to refer to a certain lifestyle, the underlying construct's definition is consumer and situation specific. The word luxury originates from the Latin term 'luxus' signifying, "soft or extravagant living, indulgence, sumptuousness or opulence" (Glare, 1992). Cornell (2002) observes that luxury is quite a slippery term to define because of the strong involvement of individual cognition and value recognition from others. Several researchers have defined luxury from the 'price - quality' and 'price - functionality' ratio perspectives, wherein highly priced products are perceived to be of good quality and high functionality (Nueno and Quelch, 1998). Kapferer (1997) suggests an experiential approach according to which, luxury items offer the potential to provide extra pleasure by flattering all senses at once. Phau and Prendergast (1999) focus on the exclusivity dimension of luxury, arguing that luxury brands compete on the ability to evoke selectiveness which in turn, has strong association with perceived quality. From the above discussion, the subjective and multidimensional nature of the luxury construct can be observed. Therefore, to explain consumer behaviour in relation to luxury brands, apart from social orientation through snobbery and conspicuousness (Mason, 1999), personal orientation such as hedonic or materialistic motives (Dubois and Laurent, 1994; Tsai, 2005) as well as, functional value associations such as quality and uniqueness (Wiedmann et al., 2007, 2009; Tsai, 2005) should be considered.

In the following sub-sections we review the literature and advance hypotheses regarding the effect of three underlying dimensions of value - social, personal and functional - on luxury purchase intentions.

\subsection{Social value perceptions}

The concept of social value orientation is rooted in research focusing on co-operation and competition. Presumably, patterns of social value perceptions could be relatively easily understood if individual consumers tended to act in accordance with their own rational self-interest (Kapferer, 1997). However, in most social interactions such motivations seem to be broader and more multifaceted than the simple quest of personal outcomes (Belk, 1985). Earlier research on social value perceptions indicates that consumers' own choices as well as their expectations of others' choices in outcome-interdependent situations varies as a function of the weight they typically assign to their own and others' outcomes (Tynan et al., 2010).

Consumers often acquire products according to what they mean to them and members of their social reference groups (Wiedmann et al., 2007, 2009). Their behaviour is subject to pressures of social norms and expectations of socialisation-oriented institutions such as those arising from family and other reference groups (Shukla, 2012). As Kapferer (1997) observes, the history of luxury consumption is deeply rooted in the notion of social stratification. Shukla (2010) argues that one of the important motivating forces that influence a wide range of consumer behaviour is the aspiration to gain status or social prestige from the acquisition and consumption of goods. Such social value-driven motivations were found to be salient across highly individualistic as well as collectivistic cultures (Shukla, 2012; Vigneron and Johnson, 2004; Wiedmann et al., 2009, Hennigs et al., 2012).

Eastman et al. (1999) suggest that consumers' status-seeking behaviour is directly related to their luxury purchase behaviour. This is also observed by O'Cass and McEwen (2004) who suggest that luxury brands may be purchased for internal reasons 
(self-reward) or external reasons (signal of wealth), and they may or may not be publicly displayed. Tsai (2005) suggests two primary motives behind luxury consumption; namely,

a social salience

b social identification.

In other words, if consuming luxury products is considered socially appropriate, consumers may have to undertake such behaviour to fit the social standards. This in turn, will help gain social advantage in the eyes of the significant others. As Kapferer (1997) asserts, the universally-observed phenomenon of social stratification (although it may vary in relative salience across nations) is central to luxury value perceptions. Therefore, it is proposed that:

H1 There is a positive relationship between a consumer's social value perceptions and luxury purchase intentions.

\subsection{Personal value perceptions}

While researchers have proposed strong association between social value perceptions and luxury consumption, one of the emerging thoughts in the area of luxury consumption is the importance of personal value perceptions (Tsai, 2005). Researchers such as Vigneron and Johnson (2004), Wiedmann et al. (2007) and Wong and Ahuvia (1998) among others, argue that personal value perceptions of consumers constitute a non-negligible segment, requiring much further study. This is also empirically tested in recent research by Shukla (2012) and Hennigs et al. (2012). Tsai (2005) also observes that while social value-related research dominates the luxury consumption literature, personal value perceptions are comparatively overlooked. It has been observed by Wong and Ahuvia (1998) that an increasing number of consumers are consuming luxury products to derive self-directed hedonic experience and symbolic benefits to the self. Such benefits are highly personal and in contrast to the social benefits focusing on impressing other people. Personal-oriented consumers are concerned with being able to identify their internal self with the product, gain an enjoyable experience from the luxury product and match their individual tastes to the product's quality (Wong and Ahuvia, 1998; Wiedmann et al., 2009). Personal-oriented consumers seek to gain self-directed pleasure from luxury consumption by focusing on the achievement of hedonic gratification and self-awareness rather than pleasing others' expectations (Tsai, 2005). Personal-oriented consumption can be conceptualised as contrasting to the motivations of collectivistic consumers, who are less likely to place emphasis on achieving personal goals to enhance self-image (Litvin and Kar, 2004). It follows that in individualistic cultures such as the USA and the UK, personal value perceptions may have a particularly strong impact on luxury consumption. In such context, the internal (hedonic) and external (materialism) facets of the self may become more pronounced. Depending on the variation in consumer personality disposition one facet (i.e. internal or external) may become more pronounced than the other in decision-making. Consumers continuously attempt to achieve a balance between these two facets by focusing on congruity with the internal self (Wiedmann et al., 2007, 2009). Researchers have found a positive impact of self-congruity on luxury purchase intentions (O'Cass and Frost, 2002). However, Tsai (2005) argues that congruity with internal self may be more pronounced in individualistic consumers (private conscious) in 
comparison to the collectivistic consumers (public conscious). Researchers also suggest that purchasing luxury products as a personal indulgence can provide a heightened positive emotional state which may elicit better feelings (Tynan et al., 2010; Shukla and Purani, 2012). Thus, it is proposed that:

H2 There is a positive relationship between a consumer's personal value perceptions and luxury purchase intentions.

\subsection{Functional value perceptions}

While luxury products may primarily be consumed for their social and personal value perceptions, it is important to remember that every product is designed to perform specific functions, in order to satisfy consumer needs. Wiedmann et al. (2007) conceptualise the importance of functional value perceptions. They suggest that consumers expect a luxury product to be usable, of good quality and unique enough to satisfy their urge to differentiate. In the domain of luxury consumption, while personal value perceptions may be driven by hedonic attitudes, functional value perceptions may be influenced by utilitarian attitudes that focus on a product's potential usability. Bennett (1984) defined usability through two distinct perspectives involving of ease of use (by subjective assessment) and effectiveness of use (by objective performance). Furthermore, Han et al. (2000) suggest that usability of a product is considered one of the most important purchasing factors. Researchers opine that high quality is also seen as a fundamental characteristic of a luxury product (Shukla, 2012) and one of the highly influential factors affecting its purchase (Hennigs et al., 2012). This is congruent with the assumption in the field of perceived quality that hand-made luxury brands offer excellent product quality and performance as compared to non-luxury brands (Dubois and Laurent, 1994; Vigneron and Johnson, 2004). Thus, on account of this, consumers may associate luxury products with a superior brand quality and trust so that they receive more value from such consumption. Consequently, increased functional value may predict higher perceptions of a luxury product's monetary or financial value, especially over time. The luxury watch brand Patek Phillippe, for example, advertises itself as an inter-generational investment to be, "merely looked after for the next generation" and the antithesis to self-centred gratification. Likewise moving away from conspicuous consumption and stressing durable and unique craftsmanship, Hermes focuses on marketing unique but timeless products with exceptional functional utility that will last a lifetime.

Wiedmann et al. (2007) propose that an individual's need for uniqueness plays a fundamental role in consumption of luxury products. Similarly, Shukla (2012) argues that as a product's perceived uniqueness increases the value of the product increases too, leading to improving an individual's standing in the societal hierarchy. However, Mason (1999) and Wiedmann et al. (2007) suggest that little is known about the influence of functional factors on luxury consumption requesting further empirical testing. Therefore, it is proposed that:

H3 There is a positive relationship between a consumer's functional value perceptions and luxury purchase intentions.

Following the above stated hypotheses the proposed model is depicted in Figure 1: 
Figure 1 Model overview

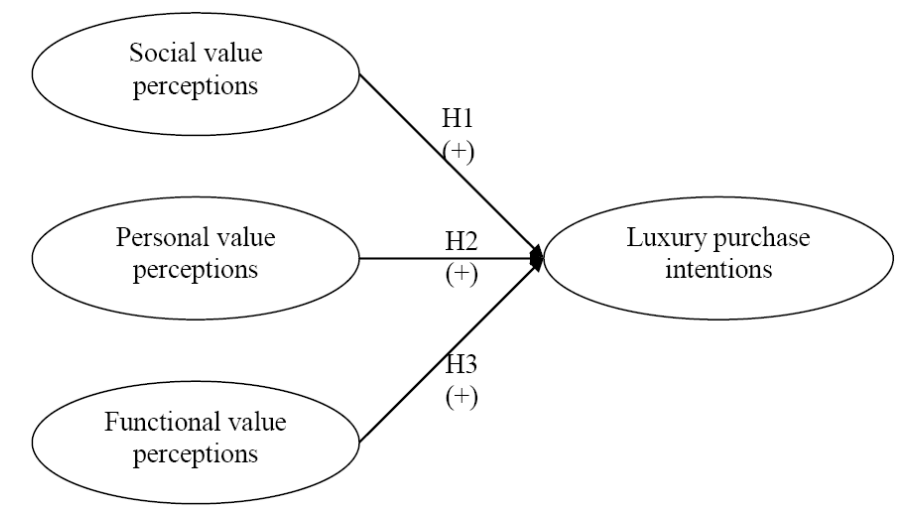

\section{Methodology}

Data for this study were obtained via separate mall intercept surveys carried out in the UK and the USA. Both are highly-developed, lead markets for luxury products. It is believed that the USA and the UK represent $17 \%$ and $5 \%$ of the global luxury market respectively (Allen, 2007; Datamonitor, 2009) and cities like New York and London are seen as a global hubs and lead markets for the evolution of luxury trends (Gower, 2008). As such, consumer perceptions and behaviours in the UK and the US project a high degree of opinion leadership affecting consumers in other markets, helping to define consumption trends worldwide. In testing the model on cross-national data, the study responded to calls for more work of this nature in the area of luxury consumption (Dubois et al., 2005; Wiedmann et al., 2009).

A concern may be raised that both USA and the UK are fairly similar on the various cultural dimensions proposed by Hofstede and Hofstede (2004); however it has been observed that they differ significantly on their achievement and ascription orientation as well as task and person orientation as suggested by Trompenaars and Hampden-Turner (1998). Moreover, both Hofstede and Hofstede (2004) and Trompenaars and Hampden-Turner (1998) urge caution in concluding similarity among the consumer-level constructs (as measured in this study) to the national-level constructs (as measured in their studies which focused on managers). They also assert that contextual differences (i.e. acting as manager in one case to consumer in another case) may play a significant role in the change in consumer behaviour.

Although, we only use two countries in this study, the current study highlights cross-national stability of the proposed hypotheses. With our data being cross-national in nature, research issues pertaining to cross-national equivalence became a major concern. We paid particular attention to the issues of conceptual, functional, measure, sample and data collection equivalence as suggested by Steenkamp and Baumgartner (1998). This has been highlighted in the following discussion. 


\subsection{Questionnaire development}

To test the hypotheses, a structured questionnaire was designed focusing on proposed value perceptions and their impact on luxury purchase intentions. In developing the research instrument the procedure proposed by Douglas and Craig (1983) for conducting international marketing research was followed. The questionnaire was divided into two sections. The first section focused on demographic details and the second on the luxury value perceptions and purchase intentions. The initial sets of items were derived from established measurement scales. Questions relating to social value perceptions were derived from O'Cass and McEwen (2004), Shukla (2010) and Truong et al. (2008). An additional item was added in the scale depicting 'luxury brands make me feel acceptable in my work circle'. The scale items relating personal value perceptions were derived from Tsai (2005) and Wiedmann et al. (2009). The functional scale items were derived from Voss et al. (2003) and Tsai (2005). A self-reported measure as suggested by Cronin and Taylor (1992) was used for purchase intentions. All measures employed a five-point Likert-type response format, with 'strongly disagree' and 'strongly agree' as anchors. Further, the survey questions asked respondents to focus their value perceptions on luxury 'accessories', as opposed to apparel. This operationalisation was chosen given the centrality of accessories to consumer self-expression, as the same accessory can be utilised in diverse settings, complementing multiple pieces of apparel across occasions.

The conceptual and functional equivalence for all constructs was assessed subjectively by the research team members. Efforts in this respect were greatly helped by the multicultural composition of the team. These scales were evaluated by a panel of expert judges for content and face validity as suggested by Zaichkowsky (1985). The questionnaire was then submitted to two academics who were asked to assess each item for representativeness, specificity and clarity which in turn added to the overall content and face validity. The questionnaire was pilot tested $(n=20)$ to identify any impolite, unclear or difficult to understand questions. The questionnaire was distributed in Greater London and Sussex, UK and New York, USA. Respondents were contacted on the high streets in both places and were requested to participate. The high streets were chosen because of the dense traffic, wide assortment of luxury product categories sold and large degree of store browsing among consumers (Beatty and Ferrell, 1998). The data was collected over a five-week period with the survey team rotating the location of interviews, the times of the day and the days of the week to make the final sample representative of the population of shoppers. More than 1200 respondents were contacted, of which 357 participated in the UK study while 285 participated in the USA. After cleaning the data the final usable sample was 299 for the UK and 201 for the USA representing response rates of $49.83 \%$ and $33.50 \%$ for the UK and the USA respectively. Table 1 provides the details of the respondent profile in both countries.

According to Table 1, 61.80\% of respondents in the USA and $50.30 \%$ of the respondents in the UK belong to the age group 21-30. The US respondents group was fairly balanced with regard to gender (male $=49.68 \%$; female $=50.32 \%$ ) while it was little skewed towards females in the UK sample (male $=39.00 \%$; female $=61.00 \%$ ). The UK sample has less singles in comparison to the USA (US - UK difference $=13.71 \%$ ) however more married consumers (UK - US difference $=14.59 \%$ ). Both countries demonstrated similar pattern in terms of family size with more than half the respondents living in households of 2 or less. The education profile was also found to be fairly similar across the nations. 
Table 1 Respondent profile

\begin{tabular}{lcc}
\hline & $U S A$ & $U K$ \\
\hline Age & & \\
$21-30$ & $61.80 \%$ & $50.30 \%$ \\
$31-40$ & $23.80 \%$ & $22.60 \%$ \\
$41-50$ & $11.40 \%$ & $19.50 \%$ \\
51 and above & $3.00 \%$ & $7.60 \%$ \\
Gender & & \\
Male & $49.68 \%$ & $39.00 \%$ \\
Female & $50.32 \%$ & $61.00 \%$ \\
Marital status & & \\
Single & $56.21 \%$ & $42.50 \%$ \\
Married & $17.91 \%$ & $32.50 \%$ \\
Divorced & $3.98 \%$ & $6.50 \%$ \\
Living with partner & $21.90 \%$ & $18.50 \%$ \\
Family size & & \\
2 or less & $61.00 \%$ & $54.00 \%$ \\
3 to 5 & $34.50 \%$ & $45.00 \%$ \\
6 and above & $4.50 \%$ & $1.00 \%$ \\
Education & & \\
Diploma or certificate & $21.89 \%$ & $27.00 \%$ \\
Graduate or equivalent & $41.79 \%$ & $37.50 \%$ \\
Post graduate and above & $36.32 \%$ & $35.50 \%$ \\
\hline
\end{tabular}

\subsection{Measure assessment}

The data were first checked for normality, outliers and multicollinearity following the method suggested by Pallant (2004), however no discrepancies were observed. Initial purification of the scales was undertaken using exploratory factor analysis. Confirmatory factor analysis using LISREL was employed to assess the unidimensionality and discriminant validity of the constructs for both the UK and the US samples. To examine the construct equivalence among both samples, two-group confirmatory factor analysis was performed as suggested by Durvasula et al. (1993). Several items were eliminated from the scales in order to achieve appropriate levels of invariance across the samples. The final set of items and corresponding loadings estimates is provided in Appendix.

As mentioned in Table 2, the coefficient $\alpha$ across the social, personal and functional scales exceeded the threshold value of 0.7 (Nunnally, 1978), implying reliability of the three constructs. The average variance extracted for the measures was found to be 0.5 and above for all constructs, which is greater than the recommended level by Dillon and Goldstein (1984). Discriminant validity was assessed using the test suggested by Fornell and Larcker (1981). This test suggests that a scale possesses discriminant validity if the average variance extracted by the underlying latent variable is greater than the shared variance (i.e. the squared correlation) of a latent variable with other latent variable. As 
shown in Table 2, this criterion was met by all of the variables in the study as no correlation exceeds the square root of the average variance extracted. The composite reliability was found to be above 0.7 across the constructs, exceeding the recommended threshold value, which also provides strong evidence of discriminant validity.

Table 2 Coefficient $\alpha$, CR, AVE and correlation matrix

\begin{tabular}{lcccccc}
\hline & $\alpha$ & $C R$ & $A V E$ & Social & Personal & Functional \\
\hline USA & & & & & & \\
Social & 0.82 & 0.83 & 0.69 & 0.83 & & \\
Personal & 0.78 & 0.88 & 0.79 & 0.61 & 0.89 & \\
Functional & 0.71 & 0.83 & 0.71 & 0.40 & 0.41 & 0.84 \\
UK & & & & & & \\
Social & 0.90 & 0.89 & 0.82 & 0.91 & & \\
Personal & 0.77 & 0.87 & 0.77 & 0.66 & 0.88 & \\
Functional & 0.81 & 0.88 & 0.81 & 0.59 & 0.62 & 0.90 \\
\hline
\end{tabular}

\section{Analysis and results}

Cross-national invariance of the scales (configural, matric and factor variance invariance) was then assessed using procedures outlined by Steenkamp and Baumgartner (1998). Configural invariance means that the factor loadings specified are significant across both samples. Metric invariance implies that the factor loadings are equal in both samples. Finally, factor variance invariance occurs when the variance of the latent variable is equal in both samples. The scales were assessed for invariance individually using confirmatory factor analysis. The results across the two samples indicated that the factor loadings are invariant, providing empirical evidence of construct equivalence.

As seen in Table 3, the model fit the data well suggesting support for configural invariance. Factor loadings were set to be invariant across nations, for measuring the full metric invariance model. The results showed a non-significant increase in chi-square $\left(\Delta \chi^{2}(10)=16.03 ; p>0.05\right)$ with other fit statistics remaining significantly above the recommended value, suggesting full metric invariance has been achieved. Full scalar invariance is rare in cross-cultural studies (Strizhakova et al., 2008). Therefore, partial scalar invariance was calculated following the method suggested by Steenkamp and Baumgartner (1998). The $\chi^{2}$ difference between the configural invariance model and partial scalar model was $\Delta \chi^{2}(19)=25.97(p>0.05)$. Moreover, all other fit values stayed above the recommended values suggesting that partial scalar invariance has been achieved across the samples. Additional analysis was conducted to establish whether an improvement in overall model fit could be obtained by relaxing some of the path invariance constraints. A series of 'partially restricted' models that restrict path coefficients one-at-a-time to be equal across the two samples were estimated as suggested by Singh (1995). Each partially restricted model test statistic and fit indexes were 
examined relative to the fully unrestricted model. However, no path was observed that further improved the model fit.

Table 3 Fit measures for the fully restricted and fully unrestricted models

\begin{tabular}{lccccccc}
\hline Model & $\chi^{2}(d f)$ & $\Delta \chi^{2}(\Delta d f)$ & $R M S E A$ & $N N F I$ & $C F I$ & $G F I$ & $\chi^{2} / d f$ \\
\hline Configural invariance model & $152.69(129)$ & - & 0.027 & 0.99 & 0.99 & 0.97 & 1.18 \\
Metric invariance model & $168.72(139)$ & $16.03(10)$ & 0.031 & 0.99 & 0.99 & 0.97 & 1.21 \\
Partial scalar invariance model & $178.66(148)$ & $25.97(19)$ & 0.047 & 0.97 & 0.98 & 0.96 & 1.21 \\
Overall constrained model & $234.34(151)$ & $55.68(3)$ & 0.047 & 0.96 & 0.98 & 0.96 & 1.55 \\
\hline
\end{tabular}

Multiple-group CFA model with mean structures was employed to test research hypotheses. To ascertain that overall mean differences in consumer luxury value perceptions existed, an overall constrained model was created in which all three latent factor means were set to equal across the samples. The overall constrained model was compared with the partial scalar invariance model. The chi-square difference was highly significant $\left(\Delta \chi^{2}(3)=55.68 ; \mathrm{p}<0.01\right)$ suggesting significant overall mean differences existed across the nations. The path coefficient analysis (Table 4) clearly shows the structure of relationships hypothesised in this study. Partial empirical support was found for Hypothesis 1 that focused on impact of social value perceptions on luxury purchase intentions. The relationship was found to be positively significant only for the USA $(p<0.01)$. In order to test the differences, a constrained model wherein only the social value factor means were set to be invariant was compared with the partial scalar invariance model. The chi-square was significant $\left(\Delta \chi^{2}(1)=11.52 ; \mathrm{p}<0.001\right)$. The finding demonstrates that social value perceptions strongly influence American consumers. However, they are non-significant in the case of British consumers. Partial empirical support was found for Hypothesis 2 relating to personal value perceptions and its impact on luxury purchase intentions supported across the UK $(\mathrm{p}<0.01)$ but not in the USA. To test for the difference between countries, personal value factor means were set to be invariant in the constrained model. The chi-square was found to be highly significant $\left(\Delta \chi^{2}(1)=12.44 ; p<0.001\right)$ suggesting consumers in the UK gave higher importance to personal values in comparison to their US counterparts. Lastly, functional value perceptions were also found to be significant predictors of luxury purchase intentions in both the UK $(\mathrm{p}<0.01)$ and the USA $(\mathrm{p}<0.01)$. The chi-square difference test was significant $\left(\Delta \chi^{2}(1)=12.50 ; \mathrm{p}<0.001\right)$. This demonstrates that the British consumers are more influenced by functional value perceptions in comparison to their American counterparts.

Table 4 Summary of results

\begin{tabular}{lcccc}
\hline \multirow{2}{*}{ Path } & \multirow{2}{*}{\begin{tabular}{c} 
Sypothesis \\
\cline { 3 - 4 }
\end{tabular}} & & \multicolumn{2}{c}{$\begin{array}{c}\text { Standardised estimates } \\
\text { (t-values) }\end{array}$} \\
\cline { 3 - 5 } Social value $\rightarrow$ Luxury purchase intentions & $\mathrm{H} 1$ & $0.11(0.72)$ & $0.35^{*}(2.09)$ \\
Personal value $\rightarrow$ Luxury purchase intentions & $\mathrm{H} 2$ & $0.36^{*}(1.97)$ & $0.34(1.64)$ \\
Functional value $\rightarrow$ Luxury purchase intentions & $\mathrm{H} 3$ & $0.46^{*}(3.37)$ & $0.37^{*}(2.83)$ \\
\hline
\end{tabular}

Notes: ${ }^{*} \mathrm{p}<0.05$. Since all hypotheses are directional, we use one-tailed tests. 


\section{Discussion and conclusions}

Our empirical results represent an attempt in the Marketing literature to study the simultaneous effect of various dimensions of luxury value perceptions on luxury purchase intentions in a cross-national context. Further, and to the best of our knowledge, this is specifically the first empirical verification of a multi-dimensional conceptual framework of luxury value perceptions, simultaneously tested in a cross-national context among two large and leading luxury markets. Overall, the empirical findings support the view that social, personal and functional value perceptions play key roles in consumers' luxury purchase intentions across both highly-developed, lead luxury markets. Our findings have important implications for marketing managers of luxury brands with regard to building marketing strategy.

\subsection{Theoretical implications}

The current study provides evidence to suggest that, analogous to the initial expectations, influence of value perceptions on purchase intentions may be common across cultures and nations however their degree of influence may be unique to each culture or nation. A cultural meaning-based explanation as to why social value perceptions were found to have a significant impact in the USA but not in the UK, may lie in that the British society has a longer tradition and influence of hierarchical classes such as 'old money' (versus a preponderance of 'new money' in the USA) whose luxury consumption is more private rather than public. Consequently, UK luxury consumers could be expected to rest less prominence on social value perception than their more aspirational US counterparts who focus highly on their achievement orientation and therefore have a higher need to identify themselves within their peer group (Trompenaars and Hampden-Turner, 1998).

The findings also provide empirical support to the argument put forward by management researchers regarding the important role played by personal value perceptions (Wiedmann et al., 2007). The finding suggests that luxury consumption is being increasingly used for self-directed pleasure and not just for the social motive of 'buying to impress others'. Significant influence of personal value perceptions among British consumers offers further empirical support to the notion put forward by Shukla (2012) that British consumers are more driven by self-directed pleasure from luxury consumption. The differential impact of social and personal value perceptions among the two countries also adds support to the suggestion by Kapferer (1997) regarding the multi-dimensionality of the luxury construct. Moreover, the findings also contribute to the debate relating to use of caution in employing national level cultural traits at the consumer decision-making level.

\subsection{Managerial implications}

Our findings have important implications for marketing managers of luxury brands. Given that functional value perceptions were found to be a significant predictor of luxury purchase intentions across both nations in our study, firms that wish to project a more standardised communications approach may wish to emphasise this dimension in their promotional strategies. Companies may also strategically elect to communicate one particular luxury value dimension in order to more clearly position and differentiate their brand from the competition. Brands that wish to pursue an affordable luxury position may 
elect to highlight functional value, while those, such as Hermes, who prefer an image of exclusivity or scarcity, should project customised offering based on personal value perceptions.

The significant impact of personal value perceptions holds particularly important strategic implications for luxury brand managers. While most marketing efforts for luxury goods have revolved around enhancing social status (Truong et al., 2008) there is an increasing need to cater to a consumer's self-directed pleasure. This in turn, may provide managers a distinct positional advantage in consumer minds and create an opportunity for differentiation. It is also observed that the impact of personal value perceptions is greater in the UK in comparison to the USA. Both the UK and the US score very similarly on individualism score (the UK $=89$ and the USA $=91$; Hofstede and Hofstede, 2004). However, the dissimilarity in personal value perceptions suggests the need to adapt to the minute but significant differences across nations.

The functional value perceptions were found to be the strongest predictors of luxury purchase intentions across both markets. This we believe is a contextual response from consumers in the light of the current economic downturn and increased consumer emphasis on sustainability. For instance, much recent literature in the business press suggests a potentially negative shift in attitudes toward luxury goods and materialism in general, resulting in consumers equating luxury goods with increased functional scrutiny (Economist, 2009). This in turn, provides a greater opportunity for luxury brand managers in highlighting the quality, uniqueness and enduring value of their products and brands.

Overall, the study makes several important contributions. First, this is the first of its kind empirical study focusing on the impact of value perceptions on luxury purchase intentions in a cross-national context. Secondly, the findings of this research may have implications for cross-national luxury consumption theory and practice, corroborating the belief associated with the multi-dimensionality of the luxury construct. Furthermore, it also contributes to the theoretical debate that several key constructs may be common among all cultures and countries while others must be adjusted for the unique national distinctions (Wong and Ahuvia, 1998). This study further affirms the need for understanding cross-national idiosyncrasies and differences for managers managing luxury brands. Thirdly, while global economic uncertainty has gripped most nations and will do so for the coming few years, the findings of this study provide luxury brand managers avenues to deal with such downturns. The findings provide multiple brand positioning and differentiation opportunities for luxury brand managers. Lastly, the constructs and measurements developed for this study can help serve as a base for further such cross-national research relating to luxury consumption and the role played by value perceptions.

\subsection{Limitations and directions for future research}

While our data supported the multi-dimensionality of luxury value perceptions, we used samples in only two nations, limiting the generalisability of our findings. Future studies should conduct empirical verification of our conceptual model across a wider array of nations in terms of economic as well as cultural domains. It would be quite interesting to empirically examine the effect of different levels of individualism and collectivism, uncertainty avoidance and power distance on the relative impact of personal, functional 
and social value perceptions respectively. Chattalas and Garcia (2009) for instance, found that consumers in cultures with a higher level of collectivism exhibit more favourable evaluations of utilitarian (i.e. functional) products as well as, less favourable attitudes toward hedonic (i.e. personal-oriented) consumption.

Since luxury consumption empirical research is still evolving in its embryonic stage, we offer the following research propositions based on Hofstede's (1991) cultural typology and building on this study's findings that could be tested in future research involving a wider range of nations:

1 social value perceptions have a more (less) significant positive impact on luxury purchase intentions across collectivistic (individualistic) nations

2 social value perceptions have a more (less) significant positive impact on luxury purchase intentions across high (low) power-distant nations

3 personal value perceptions have a more (less) significant positive impact on luxury purchase intentions across individualistic (collectivistic) nations

4 functional value perceptions have a more (less) significant positive impact on luxury purchase intentions across collectivistic (individualistic) nations

5 functional value perceptions have a more (less) significant positive impact on luxury purchase intentions across high (low) uncertainty avoidance nations.

Future studies could also be extended to luxury product operationalisations beyond accessories that may include high-contact services such as travel and tourism experiences, as well as products which vary in their degree of perceived hedonicness and utilitarianism. Future studies can also focus on the interaction effects between value perceptions in various cross-industry, cross-national and cross-cultural contexts. Research is also necessary to delineate boundary conditions of the effect of each of the value dimensions on luxury consumption. Furthermore, the potentially differential impact of value perceptions on luxury purchase intentions between 'old and new money' consumer classes should be investigated across nations with different levels of economic and social development. Additionally, it would be interesting to examine the dynamic evolution of the impact of value perceptions on luxury consumption over time. Specifically, the longitudinal significance of social, personal and functional value dimensions in the light of increased consumer emphasis on sustainability should be explored. For instance, much recent literature in the business press suggests a potentially negative shift in attitudes toward luxury goods and materialism in general, resulting in at least some consumers equating luxury with triviality, excess and conspicuousness (Economist, 2009). This seemingly temporary shift may be in fact signalling a long-term declining impact of social value perceptions on luxury consumption. Moreover, it may also point towards the changing perceptions about purchasing and possessing luxury goods as being socially irresponsible and unsustainable and thus of potentially negative social value, among at least a segment of consumers in more egalitarian (i.e. low power-distant) nations. Conversely, the construct of luxury value is being organically reshaped as new consumers experience 'luxury' in emerging markets. Such assumptions should also be tested using empirical studies. 


\section{References}

Ait-Sahalia, Y., Parker, J.A. and Yogo, M. (2004) 'Luxury goods and the equity premium', Journal of Finance, Vol. 59, No. 6, pp.2959-3004.

Allen, K. (2007) 'Despite the turmoil, conspicuous consumption is still in vogue', The Guardian [online] http://business.guardian.co.uk/story/0,2160310,00.html (accessed 28 September 2010).

Beatty, S.E. and Ferrell, M.E. (1998) 'Impulse buying: modelling its precursors', Journal of Retailing, Vol. 74, No. 2, pp.161-167.

Belk, R.W. (1985) 'Materialism: trait aspects of living in the material world', Journal of Consumer Research, Vol. 12, No. 3, pp.265-280.

Bennett, J.L. (1984) 'Managing to meet usability requirements: establishing and meeting software development goals', in Bennett, J.L., Case, D., Sandelin, J. and Smith, M. (Eds.): Visual Display Terminals: Usability Issues and Health Concerns, pp.161-184, Prentice Hall, Englewood Cliffs.

Chattalas, M. and Garcia, C. (2009) 'The effects of collectivism on utilitarian versus self-oriented luxury consumption', Proceedings of the European Marketing Academy Annual Conference, Nantes, France.

Cornell, A. (2002) 'Cult of luxury: the new opiate of the masses', Australian Financial Review, 27 April, p.47.

Cronin, J. and Taylor, S. (1992) 'Measuring service quality: a re-examination and extension', Journal of Marketing, Vol. 56, No. 3, pp.55-68.

Datamonitor (2009) Apparel, Accessories \& Luxury Goods Industry Profile: Global, Datamonitor, London.

Dillion, W.R. and Goldstein, M. (1984) Multivariate Analysis: Methods and Applications, Wiley, New York.

Douglas, S.P. and Craig, S.C. (1983) International Marketing Research, Prentice-Hall, Englewood Cliffs.

Dubois, B. and Laurent, G. (1994) 'Attitudes toward the concept of luxury: an exploratory analysis', Asia-Pacific Advances in Consumer Research, Vol. 1, No. 2, pp.273-278.

Dubois, B., Czellar, S. and Laurent, G. (2005) 'Consumer segments based on attitudes toward luxury: empirical evidence from twenty countries', Marketing Letters, Vol. 16, No. 2, pp.115-128.

Durvasula, S., Andrews, C.J., Lysonski, S. and Netemeyer, R.G. (1993) 'Assessing the cross-national applicability of consumer behavior models: a model of attitude toward advertising in general', Journal of Consumer Research, Vol. 19, No. 4, pp.626-636.

Eastman, J.K., Goldsmith, R.E. and Flynn, L.R. (1999) 'Status consumption in consumer behaviour: scale development and validation', Journal of Marketing Theory and Practice, Vol. 7, No. 3, pp.41-51.

Economist (2009) LVMH in the Recession: The Substance of Style [online] http://www.economist. com/displaystory.cfm?story_id=14447276 (accessed 14 October 2010).

Fornell, C. and Larcker, D.F. (1981) 'Evaluating structural equation models with unobservable variables and measurement error', Journal of Marketing Research, Vol. 18, No. 1, pp.39-50.

Glare, P.G.W. (1992) Oxford Latin Dictionary, Clarendon Press, Oxford.

Gower, I. (2008) Market Forecasts: Clothing \& Personal Goods, Key Note, London.

Han, S.H., Hwan Yun, M., Kim, K.J. and Kwahk, J. (2000) 'Evaluation of product usability: development and validation of usability dimensions and design elements based on empirical models', International Journal of Industrial Ergonomics, Vol. 26, No. 4, pp.477-488. 
Hennigs, N., Wiedmann, K.P., Klarmann, C., Strehlau, S., Godey, B., Pederzoli, D., Neulinger, A., Dave, K., Aiello, G., Donvito, R., Taro, K., Taborecka-Petrovicova, J., Santos, C.R., Jung, J. and Oh, H. (2012) 'What is the value of luxury? A cross-cultural consumer perspective', Psychology \& Marketing, Vol. 29, No. 6, pp.1018-1034.

Hofstede, G. (1991) Cultures and Organizations: Software of the Mind, McGraw-Hill, London.

Hofstede, G. and Hofstede, G.J. (2004) Cultures and Organizations: Software for the Mind, McGraw-Hill, London.

Kapferer, J.N. (1997) 'Managing luxury brands', Journal of Brand Management, Vol. 4, No. 4, pp.251-260.

Litvin, S.W. and Kar, G.H. (2004) 'Individualism/collectivism as a moderating factor to the self-image congruity concept', Journal of Vacation Marketing, Vol. 10, No. 1, pp.23-32.

Mason, R.S. (1999) The Economics of Conspicuous Consumption: Theory and Thought Since 1700, Edward Elgar Publishing, London.

Nueno, J.L. and Quelch, J.A. (1998) 'The mass marketing of luxury', Business Horizons, Vol. 41, No. 6, pp.61-68.

Nunnally, J.C. (1978) Psychometric Theory, 2nd ed., McGraw-Hill, New York.

O'Cass, A. and Frost, H. (2002) 'Status brands: examining the effects of non-product-related brand associations on status and conspicuous consumption', Journal of Product \& Brand Management, Vol. 11, No. 2, pp.67-88.

O'Cass, A. and McEwen, H. (2004) 'Exploring consumer status and conspicuous consumption', Journal of Consumer Behaviour, Vol. 4, No. 1, pp.25-39.

Pallant, J. (2004) SPSS Survival Manual: Version 12, Open University Press, New York.

Phau, I. and Prendergast, G.P. (1999) Consuming Luxury Brands: The Relevance of the 'Rarity Principle', Hong Kong Baptist University Business Research Centre, Hong Kong.

Shukla, P. (2010) 'Status consumption in cross-national context: socio-psychological, brand and situational antecedents', International Marketing Review, Vol. 27, No. 1, pp.108-129.

Shukla, P. (2012) 'The influence of value perceptions on luxury purchase intentions in developed and emerging markets', International Marketing Review, Vol. 29, No. 6, pp.574-596.

Shukla, P. and Purani, K. (2012) 'Comparing the importance of luxury value perceptions in crossnational contexts', Journal of Business Research, Vol. 65, No. 10, pp.1417-1424.

Singh, J. (1995) 'Measurement issues in cross-national research', Journal of International Business Studies, Vol. 26, No. 3, pp.597-619.

Steenkamp, J-B.E.M. and Baumgartner, H. (1998) 'Assessing measurement invariance in cross-national consumer research', Journal of Consumer Research, Vol. 25, No. 1, pp.78-107.

Strizhakova, Y., Coulter, R.A. and Price, L.L. (2008) 'Branded products as a passport to global citizenship: perspectives from developed and developing markets', Journal of International Marketing, Vol. 16, No. 4, pp.57-85.

Trompenaars, A. and Hampden-Turner, C. (1998) Riding The Waves of Culture: Understanding Diversity in Global Business, McGraw-Hill, London.

Truong, Y., Simmons, G., McColl, R. and Kitchen, P.J. (2008) 'Status and conspicuousness - are they related? Strategic marketing implications for luxury brands', Journal of Strategic Marketing, Vol. 16, No. 3, pp.189-203.

Tsai, S.P. (2005) 'Impact of personal orientation on luxury-brand purchase value', International Journal of Market Research, Vol. 47, No. 4, pp.177-206.

Tynan, C., McKechnie, S. and Chhuon, C. (2010) 'Co-creating value for luxury brands', Journal of Business Research, Vol. 63, No. 11, pp.1156-1163.

Vigneron, F. and Johnson, L.W. (2004) 'Measuring perceptions of brand luxury', Journal of Brand Management, Vol. 11, No. 6, pp.484-508. 
Voss, K.E., Spangenberg, E.R. and Grohmann, B. (2003) 'Measuring the hedonic and utilitarian dimensions of consumer attitude', Journal of Marketing Research, Vol. 40, No. 3, pp.310-320.

Wiedmann, K.P., Hennigs, N. and Siebels, A. (2007) 'Measuring consumers' luxury value perception: a cross-cultural framework', Academy of Marketing Science Review, Vol. 7, pp.1-21.

Wiedmann, K.P., Hennigs, N. and Siebels, A. (2009) 'Value-based segmentation of luxury consumption behavior', Psychology and Marketing, Vol. 26, No. 7, pp.625-651.

Wong, N.Y. and Ahuvia, A.C. (1998) 'Personal taste and family face: luxury consumption in Confucian and western societies', Psychology \& Marketing, Vol. 15, No. 5, pp.423-441.

Zaichkowsky, J.L. (1985) 'Measuring the involvement construct', Journal of Consumer Research, Vol. 12, No. 3, pp.341-352.

Zeithaml, V.A. (1988) 'Consumer perceptions of price, quality, and value: a means-end model and synthesis of evidence', Journal of Marketing, Vol. 52, No. 1, pp.2-22.

\section{Appendix}

List of survey items

\begin{tabular}{lcc}
\hline & UK & USA \\
\cline { 2 - 3 } & $\begin{array}{c}\text { Loadings } \\
\text { estimates }\end{array}$ & $\begin{array}{c}\text { Loadings } \\
\text { estimates }\end{array}$ \\
\hline Social value perceptions & 0.75 & 0.60 \\
$\quad$ I wear luxury accessories to impress other people & 0.79 & 0.72 \\
Owning this luxury accessories indicate a symbol of prestige & 0.81 & 0.81 \\
I would buy a luxury accessory just because it has status & 0.85 & 0.76 \\
$\begin{array}{l}\text { I would pay more for a luxury accessory if it has status } \\
\text { The status of a luxury accessory is irrelevant to me (-) }\end{array}$ & 0.54 & 0.61 \\
$\begin{array}{l}\text { Luxurious accessories are important to me because they } \\
\text { make me feel acceptable in my work circle }\end{array}$ & 0.76 & 0.52 \\
Personal value perceptions & & 0.74 \\
$\begin{array}{l}\text { The more luxury accessories I own, the happier I am } \\
\text { It sometimes bothers me quite a bit that I can't afford to buy } \\
\text { all the things that I want }\end{array}$ & 0.56 & 0.54 \\
$\begin{array}{l}\text { When purchasing for luxury accessories I am able to forget } \\
\text { about my problems }\end{array}$ & 0.79 & 0.77 \\
$\begin{array}{l}\text { Luxury accessories make me a fashion leader rather than a } \\
\text { fashion follower }\end{array}$ & 0.75 & 0.63 \\
$\begin{array}{l}\text { During purchasing luxury accessories, I feel the excitement of } \\
\text { the hunt }\end{array}$ & 0.57 & 0.81 \\
$\begin{array}{l}\text { When in a bad mood I may buy luxury accessories to enhance } \\
\text { my mood }\end{array}$ & 0.73 & 0.77 \\
I purchase luxury accessories to reflect my own image & 0.72 & 0.73 \\
\hline
\end{tabular}

Note: $(-)=$ reverse coded item. 


\section{List of survey items (continued)}

\begin{tabular}{lcc}
\hline & UK & USA \\
\cline { 2 - 3 } & $\begin{array}{c}\text { Loadings } \\
\text { estimates }\end{array}$ & $\begin{array}{c}\text { Loadings } \\
\text { estimates }\end{array}$ \\
\hline Functional value perceptions & & \\
$\quad$ I am very attracted to unique luxury accessories & 0.79 & 0.70 \\
I am more likely to buy luxury accessories that are unique & 0.83 & 0.80 \\
I dislike luxury accessories that everyone else has & 0.63 & 0.53 \\
The quality of a luxury accessory is important to me & 0.78 & 0.62 \\
The luxury accessories superior quality is my major reason & 0.78 & 0.85 \\
for purchasing them & & \\
\hline
\end{tabular}

Note: $(-)=$ reverse coded item. 